\title{
Interferon- $\alpha$ and Interleukin 2 Synergistically Enhance Basic Fibroblast Growth Factor Synthesis and Induce Release, Promoting Endothelial Cell Growth
}

\author{
Federico Cozzolino, * Maria Torcia, * Maria Lucibello, * Lucia Morbidelli," Marina Ziche," \\ Jeffrey Platt," Silvia Fabiani, * Jerry Brett," and David Stern" \\ *Dipartimento di Medicina Sperimentale e Scienze Biochimiche, University of Rome "Tor Vergata," I-00173 Rome, Italy; \\ ${ }^{\ddagger}$ Dipartimento di Farmacologia, University of Florence, I-50136 Florence, Italy; ${ }^{\S}$ Department of Surgery, Duke University, \\ Durham, North Carolina 27710; and "Department of Physiology, Columbia University, New York, 10032
}

\section{Abstract}

To elucidate mechanisms underlying neovascularization that accompanies certain chronic immune/inflammatory disorders, the effects of interferon- $\alpha($ IFN- $\alpha)$ and interleukin 2 (IL-2) on endothelial cell (EC) growth in vitro and angiogenesis in vivo were studied. Preincubation of cultured human ECs with IFN$\alpha$, followed by exposure to $\mathbf{L}-2$, resulted in effective stimulation of cell growth, whereas either cytokine alone had only a slight effect. The combination of IFN- $\alpha$ /IL-2 induced an angiogenic response in the rabbit cornea. IL-2 receptor expression was enhanced on IFN- $\alpha$-treated ECs: p55 was increased and p70 was induced. ${ }^{125}$ I-IL-2 binding to ECs treated with IFN- $\alpha$ was enhanced $\left(K_{\mathrm{d}}\right.$ from $\approx 7 \mathrm{nM}$ to $\approx 260 \mathrm{pM}$ with IFN- $\alpha$ ), and anti-p55 IgG blocked ${ }^{125}$ I-IL-2 / EC interaction as well as IL-2-mediated EC proliferation. Consistent with these findings in cell culture, immunohistologic studies demonstrated p55 and p70 antigen in the vasculature of rheumatoid joints, but not in normal joint tissue. Exposure of cultured ECs to IFN- $\alpha$ increased levels of intracellular EC basic fibroblast growth factor (bFGF), and subsequent addition of IL-2 led to bFGF release into the medium. The observation that anti-bFGF IgG largely blocked EC proliferation in response to IFN- $\alpha /$ IL-2 suggested that bFGF was a critical agent in this setting. These data suggest a mechanism rendering ECs responsive to IL-2 which may be relevant in immune/inflammatory disorders: IFN- $\alpha$-mediated induction of functional EC receptors for IL-2, which drives cell proliferation by a mechanism dependent on increased synthesis and release of bFGF. (J. Clin. Invest. 1993. 91:2504-2512.) Key words: binding sites • cell division • inflammation • neovascularization • rheumatoid arthritis

\section{Introduction}

Formation of new blood vessels is an ongoing process which subserves multiple different roles spanning early development to promotion of tumor growth $(1,2)$. The angiogenic response, including endothelial cell (EC $)^{1}$ migration and proliferation, is

Address reprint requests to Dr. Federico Cozzolino, Dipartimento di Medicina Sperimentale e Scienze Biochimiche, University of Rome "Tor Vergata," Via Orazio Raimondo, 100173 Rome, Italy.

Received for publication 24 July 1992 and in revised form 22 December 1992.

1. Abbreviations used in this paper: $\mathrm{b}$, basic; EC, endothelial cell; FGF, fibroblast growth factor; r, recombinant.

J. Clin. Invest.

(C) The American Society for Clinical Investigation, Inc. 0021-9738/93/06/2504/09 \$2.00

Volume 91, June 1993, 2504-2512 probably principally induced in vivo by a limited number of agents, such as the family of heparin-binding growth factors (3, 4 ), particularly the fibroblast growth factors (FGFs) $(5,6)$. Regulation of the production of these factors occurs in response to a myriad of environmental perturbations (3). Ingrowth of new vessels in disorders involving immune/inflammatory mechanisms, such as the rheumatoid joint or corneal pannus $(7,8)$, for example, is a situation in which multiple cytokines could modulate the vascular response. In this context, IL-1 is a cytokine which suppresses endothelial growth in vitro and angiogenesis in vivo (9), probably in large part due to suppression of high-affinity receptors for FGF.

In this report, we provide further evidence linking cytokines to the regulation of endothelial proliferation. IL-2 is shown to potently stimulate endothelial growth in vitro and blood vessel formation in vivo, after exposure of EC to interferon- $\alpha($ IFN- $\alpha)$. IFN- $\alpha$ enhances expression of the $\mathrm{p} 55$ chain of the IL-2 receptor, and induces p70, resulting in a functional EC receptor (10) with intermediate affinity for the ligand $\left(K_{\mathrm{d}}\right.$ $\approx 260 \mathrm{pM}$ ). On subsequent addition of IL-2, promotion of EC growth occurs by a mechanism that involves IL-2-mediated release of bFGF. Based on these observations, we hypothesize that IFN- $\alpha$ induces endothelial responsiveness to IL-2, altering proliferation and, probably, multiple other cellular properties as well.

\section{Methods}

Recombinant cytokines and antibodies. Purified human recombinant (r) IL-2 and rIFN- $\alpha$ were provided by Biogen (Geneva, Switzerland). Human $r$ basic (b) FGF was provided by Dr. F. Bertolero (Farmitalia, Milan, Italy). Inactivation of cytokines was accomplished by heating at $95^{\circ} \mathrm{C}$ for $20 \mathrm{~min} .{ }^{125} \mathrm{I}-\mathrm{rIL}-2$ ( $\mathrm{sp}$ act $600 \mathrm{Ci} / \mathrm{mmol}$ ) and ${ }^{125} \mathrm{I}-\mathrm{rbFGF}$ ( $\mathrm{sp}$ act $1,400 \mathrm{Ci} / \mathrm{mmol}$ ) were purchased by Amersham (Milan, Italy). IgG fraction of neutralizing anti-bFGF rabbit antisera (British Bio-Technology Ltd., Oxford, UK) and of preimmune rabbit serum were obtained by Affi-Gel Protein A (Bio-Rad Laboratories, Richmond, CA) affinity chromatography. Neutralizing mAbs against IL-2R chains p55 and p70 were obtained from Technogenetics (Milan, Italy) and from Endogen (Boston, MA), respectively; all antibodies were used at the final concentration of $5 \mu \mathrm{g} / \mathrm{ml}$ or as indicated.

Cell cultures. ECs were obtained from umbilical vein and grown as described (9). For proliferation studies, ECs (passages 2-5) were plated at $10^{4}$ per well in 24 -well plates precoated with gelatin $(0.2 \%$; Sigma Chemical Co., St. Louis, MO) for $24 \mathrm{~h}$. Cultures were then washed with HBSS, and maintained for an additional $96 \mathrm{~h}$ in medium 199 containing 20\% FCS (control medium). After this time, fresh control medium containing cytokines, bFGF, or antibodies was added, and cultures were incubated for the indicated periods. During the final $12 \mathrm{~h}$ of culture, cells were pulsed with $0.5 \mu \mathrm{Ci}$ of $\left[{ }^{3} \mathrm{H}\right]$ thymidine (sp act $25 \mathrm{Ci}$ / mmol, Amersham), and then cells were washed 10 times with HBSS and detached with trypsin, and the DNA was precipitated with trichloroacetic acid ( $10 \%$; vol $/ \mathrm{vol})$, collected on filters $(0.2 \mu \mathrm{m}$; Gelman 
Sciences, Inc., Ann Arbor, MI) and the radioactivity was determined. Exposure of endothelial cultures to IFN- $\alpha$ /IL-2 did not result in cell lysis during the proliferation studies or radioligand binding experiments (see below). This was assessed by $(a)$ exclusion of trypan blue, (b) no increase in release of lactate dehydrogenase into the culture medium, and $(c)$ the presence of an adherent cell population with no increase in floating cells.

Surface binding and internalization of ${ }^{125}$ I-labeled cytokines. For IL-2 binding studies, preconfluent cells ( $10^{6}$ in six-well plates), cultured in the presence or absence of IFN- $\alpha(500 \mathrm{pM})$ for $24 \mathrm{~h}$, were incubated for $40 \mathrm{~min}$ at $37^{\circ} \mathrm{C}$ in $1 \mathrm{ml}$ of medium 199 containing $10 \%$ FCS and $0.1 \%$ sodium azide, with different concentrations of ${ }^{125} \mathrm{I}-\mathrm{IL}-2$ alone (total binding) or with a 200-fold excess of unlabeled IL-2 (nonspecific binding). Monolayers were then washed extensively with HBSS, and membrane-bound radioactivity was eluted using glycine buffer $(0.2 \mathrm{M}, \mathrm{pH} 2.8)$ for $45 \mathrm{~s}$ at $4^{\circ} \mathrm{C}$ (neither cell lysis nor detachment occurred during the experiment or the following elution procedure). Specific binding was determined as the difference between total and nonspecific binding, and data were analyzed by nonlinear least-squares analysis using a one-site model in a scientific data analysis program (Fig. P, Biosoft, Cambridge, UK). In one set of experiments ECs were incubated as above with a fixed concentration of ${ }^{125} \mathrm{I}-\mathrm{IL}-2(0.5 \mathrm{nM})$ in the presence or absence of different concentrations of anti-IL-2R p55 $\mathrm{mAb}$ (anti-CD25).

For IL-2 internalization studies, preconfluent cells were maintained in control medium for $48 \mathrm{~h}$, stimulated with intact or heat-inactivated IFN- $\alpha(0.5 \mathrm{nM})$ for $18 \mathrm{~h}$, washed twice, and then incubated for $4 \mathrm{~h}$ more at $37^{\circ} \mathrm{C}$ in the same medium with ${ }^{125} \mathrm{I}-\mathrm{IL}-2(1 \mathrm{nM})$, in the presence or absence of 200 -fold excess of unlabeled cytokine. At the end of incubation period, cells were washed five times with HBSS. Membrane-bound radioactivity was eluted with glycine buffer as above, and the internalized (i.e., endocytosed) radioactivity was extracted by lysing the cells in PBS containing Triton X-100 (1\%).

For bFGF binding studies, preconfluent ECs grown in 24-well plates and maintained in control medium for $48 \mathrm{~h}$ were cultured for an additional $24 \mathrm{~h}$ in the presence of either IFN- $\alpha$, IFN- $\alpha$ plus IL-2 $(0.5$ nM each), or heat-inactivated cytokines. Cells were then washed and incubated for $2 \mathrm{~h}$ at $4^{\circ} \mathrm{C}$ in medium 199 supplemented with $0.2 \%$ gelatin with different concentrations of ${ }^{125} \mathrm{I}$-bFGF, in the presence or absence of a 200 -fold molar excess of unlabeled bFGF. At the end of incubation period, cultures were washed three times with PBS, once with high-salt buffer ( $2 \mathrm{M} \mathrm{NaCl}, 25 \mathrm{mM}$ Hepes, $\mathrm{pH} 7.2$ ), and then lysed with phosphate buffer $(0.1 \mathrm{M}, \mathrm{pH} 8.1)$ containing Triton X-100; binding data were analyzed as above.

For bFGF internalization studies, cultures were incubated in control medium for $48 \mathrm{~h}$, stimulated with native or heat-inactivated IFN- $\alpha$ for $18 \mathrm{~h}$, and then cells were washed twice with PBS and once with acidic buffer (medium 199 at $\mathrm{pH} 3.0$ ) for $45 \mathrm{~s}$ at $4^{\circ} \mathrm{C}$. Next, cells were incubated in control medium containing ${ }^{125}$ I-bFGF $(0.5 \mathrm{nM})$ in the presence of native or heat-inactivated IL-2 $(0.5 \mathrm{nM})$ for $2 \mathrm{~h}$ at $37^{\circ} \mathrm{C}$. Controls for nonspecific uptake of ${ }^{125}$ I-bFGF also contained 200 -fold molar excess of unlabeled bFGF. At the end of incubation, membranebound ${ }^{125}$ I-bFGF was eluted after washing in low- and high-salt buffers (see above), and internalized ${ }^{125}$ I-bFGF was subsequently released by dissolution of the monolayers with Triton X-100 (1\%; see above).

Biosynthetic labeling and immunoprecipitation studies. To assess expression of IL-2R p55 and p70 chains, and production of bFGF, preconfluent ECs $\left(\approx 3 \times 10^{6}\right)$, maintained in control medium for 48 $\mathrm{h}$, were stimulated with native or heat-inactivated IFN- $\alpha(0.5 \mathrm{nM})$. At the end of the incubation period, cells were rinsed twice in PBS, and then cultured with native or heat-inactivated rIL-2 for an additional $4 \mathrm{~h}$ in methionine- and cysteine-free MEM (GIBCO, Mascia Brunelli, Milan, Italy) supplemented with $\left[{ }^{35} \mathrm{~S}\right]$ methionine and $\left[{ }^{35} \mathrm{~S}\right]$ cysteine $(200$ $\mu \mathrm{Ci} / \mathrm{ml}$ each). Culture supernatants were collected and centrifuged, and monolayers were washed with PBS and lysed with Nonidet-P40 $(0.5 \%)$. Cell lysates and supernatants were immunoprecipitated with either the IgG fraction of rabbit monospecific anti-bFGF antibodies, the IgG fraction of preimmune rabbit antibodies, mAbs against IL-2R p55 or p70 chains, or with irrelevant mAbs of the same subclass. Then, Protein G-Sepharose ( $50 \mu \mathrm{l}$; Pharmacia, Milan, Italy) was added, the precipitate was washed five times with Tris- $\mathrm{HCl}$ buffer $(50 \mathrm{mM}, \mathrm{pH}$ 7.0 ), containing $1 \mathrm{M} \mathrm{NaCl}$ and $0.25 \%$ Nonidet-P40, boiled in Laemmli stacking buffer, and applied to SDS/PAGE. After electrophoresis, autoradiography was performed.

In selected experiments, bFGF $(35 \mu \mathrm{g} / \mathrm{ml})$ was added to both cell lysates and supernatants of labeled EC before and during the incubation with anti-bFGF antibodies. The samples were concentrated with Protein-G-Sepharose and the eluates were analyzed as above.

Pellet preparation and corneal implant. Aliquots of cytokine solutions (IFN- $\alpha, 15 \mathrm{mg} / \mathrm{ml} ; \mathrm{IL}-2,10 \mathrm{mg} / \mathrm{ml}$ ), containing the indicated amounts of IFN- $\alpha$ and/or IL-2, were evaporated to dryness at room temperature. The residual pellet was incorporated into a casting solution of Elvax-40 (10\%; Du Pont, Milan) in methylene chloride. The solvent was evaporated, and the repolymerized Elvax- 40 pellet was cut into $1 \times 1 \times 0.5-\mathrm{mm}$ fragments and further evaporated overnight under vacuum at $4^{\circ} \mathrm{C}$. The same procedure was followed for the preparation of control pellets with Elvax-40 alone.

Two parallel pockets were surgically produced onto each rabbit cornea as previously described (11). In each rabbit, one pocket in the right cornea received a pellet containing either IFN- $\alpha$ or IL-2 (in each case, $50 \mathrm{ng}$ ) and the other pocket received a pellet with polymer alone; the opposite cornea received two pellets containing either cytokine. Corneas were observed daily for new vessel growth using a slit lamp microscope. Implants were scored as inducing a positive angiogenic response if preexisting capillary vessels in the limbus increased in diameter and, after producing new vascular buds, progressed to reach the pellet. Neovascularization was apparent by day 3 after implantation of the corneal pellet, and reached the pellet within 8-10 d after surgery. Experiments were also performed with greater amounts of each cytokine alone in pellets $(100,500 \mathrm{ng}$, etc.). However, at concentrations $>100 \mathrm{ng}$ per pellet, an inflammatory response was variably observed rendering interpretation of the data difficult.

Immunopathology of tissue samples for $p 55$ and $p 70$. Tissue samples, obtained from two patients with rheumatoid arthritis as well as normal controls, were snap frozen in precooled isopentane, and frozen sections were prepared in a Lipshaw cryostat, air-dried, fixed with acetone, and washed in PBS ( $\mathrm{pH} 7.4$ ). Tissue sections were overlayed with diluted $\mathrm{mAb}$ to $\mathrm{p} 55$ and $\mathrm{p} 70$, washed and then sequentially reacted with affinity-isolated $F\left(a b^{\prime}\right)_{2}$ fragments of rabbit anti-mouse IgG (H and L) (Accurate Chemical \& Science Corp., Westbury, NY), and then with affinity-isolated, fluorescein isothiocyanate (FITC)-conjugated $F\left(a b^{\prime}\right)_{2}$ fragments of goat anti-rabbit $\operatorname{lgG}(\mathrm{H}$ and $\mathrm{L})$ (same company). Sections were counterstained with a rhodamine isothiocyanate (TRIC)-conjugated rabbit anti-human basement membrane antiserum to localize the arteriolar walls. After staining, the sections were washed with PBS and sealed in PBS containing $p$-phenylendiamine. FITC-labeled antibodies were absorbed with human serum. Control sections were prepared as described above, but omitting application of the mAbs.

\section{Results}

Effect of IFN- $\alpha$ and IL-2 on EC proliferation in vitro and in vivo. Incubation of preconfluent ECs in medium with either IL-2 or IFN- $\alpha$ alone, in the absence of an EC growth supplement, led to only a modest increase in cell growth over the 72-h period studied (Fig. 1). When ECs were exposed to both cytokines simultaneously, there was a pronounced stimulation of $\left[{ }^{3} \mathrm{H}\right]$ thymidine incorporation (Fig. 1), which was paralleled by an increase in cell number (an increase of fourfold in $\left[{ }^{3} \mathrm{H}\right]-$ thymidine incorporation was parallelled by a greater than threefold rise in cell number; data not shown). Enhancement of cell growth was dependent on the concentration of both IFN- $\alpha$ and IL-2. At fixed concentrations of IFN- $\alpha$ ( $50 \mathrm{pM}$ and 


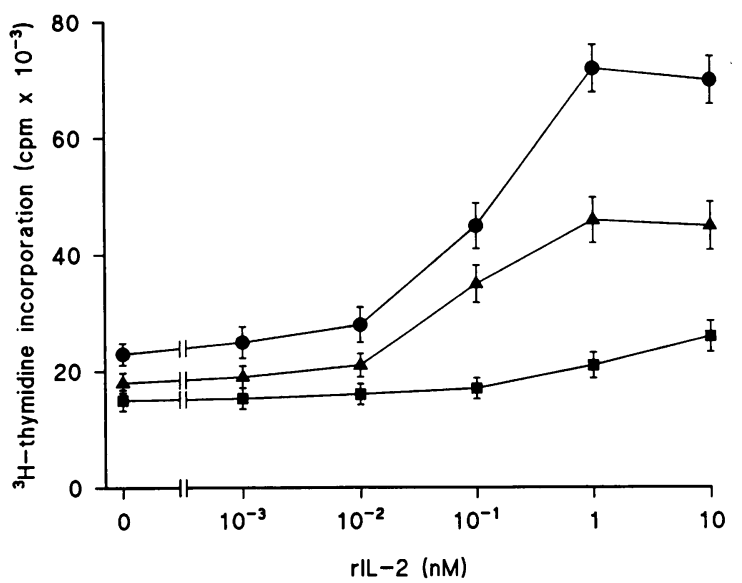

Figure 1. Effects of IL-2 and IFN- $\alpha$ on ${ }^{3} \mathrm{H}$-thymidine incorporation by cultured human ECs. Subconfluent ECs were incubated for $24 \mathrm{~h}$ in complete medium, followed by maintenance for $96 \mathrm{~h}$ in control medium. The fresh control medium containing no further addition $(\bullet), 50 \mathrm{pM}$ IFN- $\alpha(\Delta)$, or $500 \mathrm{pM} \operatorname{IFN}-\alpha(\bullet)$, was added for $72 \mathrm{~h}$. Incorporation of ${ }^{3} \mathrm{H}$-thymidine was studied as described in the text. Data shown (mean \pm SD of triplicate determinations) are the results of one representative experiment, selected from five studies.

$500 \mathrm{pM})$, the EC mitogenic response was dependent on the dose of IL-2, being half-maximal at $\approx 200 \mathrm{pM}$ and maximal by $\approx 1 \mathrm{nM}$ in each case (Fig. 1). The optimal combination of IFN- $\alpha$ ( $500 \mathrm{pM}$; higher concentrations did not give greater mitogenic effect) and IL-2 ( $1 \mathrm{nM})$ for enhancement of growth resulted in more than a fourfold increase in $\left[{ }^{3} \mathrm{H}\right]$ thymidine incorporation, whereas saturating amounts of bFGF $(500$ pM), one of the most potent stimulators of human EC growth $(5,6)$, increased $\left[{ }^{3} \mathrm{H}\right]$ thymidine labeling by about fivefold (data not shown). These data indicated that IL-2 and IFN- $\alpha$ could exert a profound, and potentially significant effect on EC growth.

To extend these observations in cell culture to the in vivo setting, the angiogenic response induced by IL- 2 and IFN- $\alpha$ was assessed in the rabbit cornea model. When studied separately, the two cytokines exhibited different angiogenic properties. IL-2 alone ( $50 \mathrm{ng}$ ) was only marginally effective, producing no response in $75 \%$ of the implants, and resulting in only sparse capillary buds, starting from the limbal region and progressing through one third of the corneal stroma underlying the pellet (Fig. 2, top) in the remaining 25\% of implants (similar results were observed at $100 \mathrm{ng}$ of IL-2). IFN- $\alpha(50 \mathrm{ng})$ was more effective in promoting capillary neoformation, in that $50 \%$ of the implanted pellets elicited formation and progression of capillaries that reached the pellet (Fig. 2, middle) (similar results were observed at $100 \mathrm{ng}$ of IFN- $\alpha$ ). When the two cytokines were tested simultaneously (each at $50 \mathrm{ng}$ per pellet), the angiogenic response was far more potent: virtually all implants exhibited neovascularization, and the number and growth rate of the newly formed vascular network was dramatically potentiated (Fig. 2, bottom).

In order to assess the mechanisms through which the combination of IFN- $\alpha$ and IL- 2 enhanced EC proliferation, cultures in control medium were preincubated with either IL-2 or IFN$\alpha$ for $18 \mathrm{~h}$, washed with HBSS, and then the effect of adding the other cytokine was studied over the next $48 \mathrm{~h}$. Cultures exposed to IL-2, and then exposed to IFN- $\alpha$, showed no increase
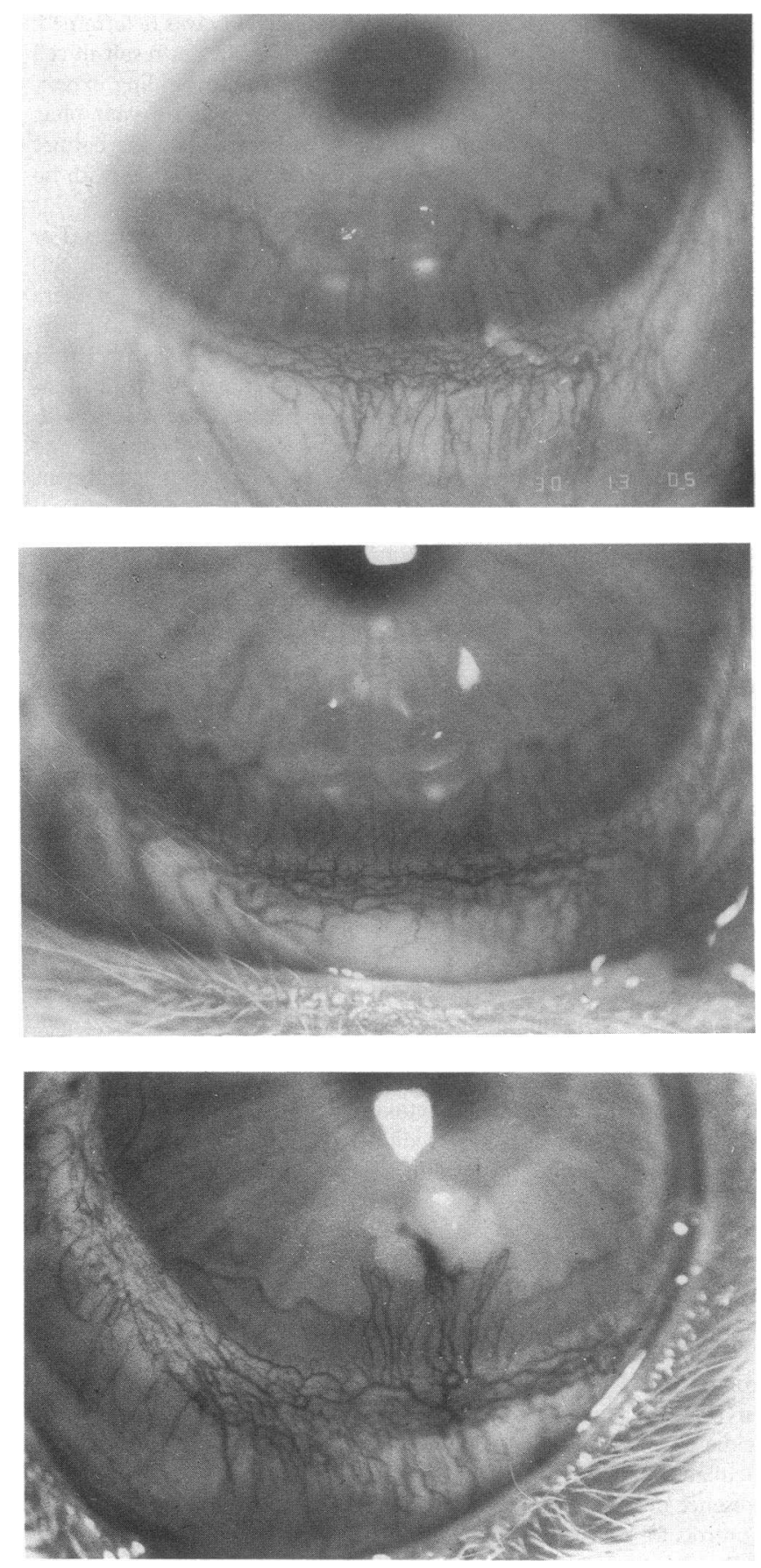

Figure 2. Angiogenic activity of IL-2 and IFN- $\alpha$ in the rabbit cornea model. Rabbit corneas were implanted with pellets containing either IL-2 alone ( $50 \mathrm{ng}$; top ), IFN- $\alpha$ alone ( $50 \mathrm{ng}$; middle), IL-2 plus IFN$\alpha$ (each at $50 \mathrm{ng} ;$ bottom ), or no addition. Photomicrographs of the corneas are shown $10 \mathrm{~d}$ later. Corneas implanted with pellets not containing any cytokines showed no significant angiogenic response. Magnification: $\times 8$.

in $\left[{ }^{3} \mathrm{H}\right]$ thymidine incorporation above that seen in control medium alone (Fig. 3). In contrast, preincubation of ECs with IFN- $\alpha$ did enhance the mitogenic response to subsequently added IL-2 (Fig. 3). The optimal preincubation time of ECs with IFN- $\alpha$ for a maximal mitogenic response on addition of 


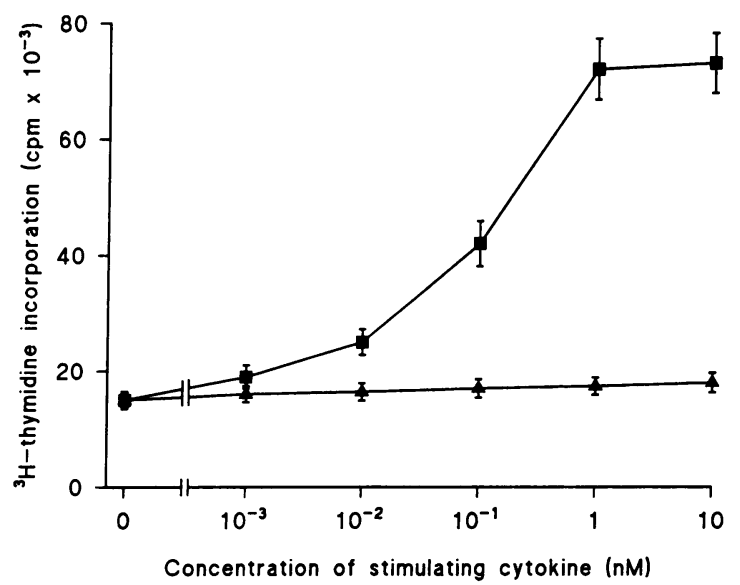

Figure 3. Effect of sequential addition of IFN- $\alpha$ and IL-2 on stimulation of endothelial ${ }^{3} \mathrm{H}$-thymidine incorporation. EC cultures were preincubated with either IFN- $\alpha(0.5 \mathrm{nM} ; \bullet)$ or IL-2 $(0.5 \mathrm{nM} ; \Delta)$ for $18 \mathrm{~h}$, washed with HBSS, and then the indicated concentration of the cytokine (either IL-2 or IFN- $\alpha$ ) to which the culture had not yet been exposed was added for $48 \mathrm{~h}$. Incorporation of ${ }^{3} \mathrm{H}$-thymidine was determined as described in the text. Data shown represent the mean \pm SD of triplicate determinations.

IL-2 was about $24 \mathrm{~h}$ (data not shown). These data suggested that IFN- $\alpha$ was priming the ECs to respond to IL-2.

Effect of IFN- $\alpha$ on EC binding sites for $I L-2$. One means through which IFN- $\alpha$ could alter the effects of IL-2 on ECs would be by modulating endothelial expression of IL-2 binding sites. Unstimulated EC monolayers incubated with ${ }^{125} \mathrm{I}-\mathrm{IL}-2$ showed dose-dependent binding, half-maximal at $\approx 7 \mathrm{nM}$ (Fig. 4). When ECs were pre-incubated with IFN- $\alpha$, the affinity of ${ }^{125} \mathrm{I}-\mathrm{IL}-2$ binding increased significantly with $K_{\mathrm{d}} \approx 260$ pM (Fig. 4). Inhibition of ${ }^{125}$ I-IL-2 binding to unstimulated and IFN- $\alpha$-treated ECs by mAb to p 55 demonstrated that the IL-2 receptor was responsible for interaction of IL-2 with endothelial cultures ( Table I).

Although the affinity of IL-2 for IFN- $\alpha$-treated ECs was lower than that of the high-affinity IL-2 receptors on lymphoid cells $\left(K_{\mathrm{d}} \approx 10 \mathrm{pM}\right)(10)$, these IL-2 binding sites appeared to be functional, based on three lines of experimental evidence. First, addition of antibody to the IL-2 receptor p55 chain blocked EC proliferation induced by IL- 2 in cultures preincubated with IFN- $\alpha$ ( Table II). Second, occupancy of these IL-2 binding sites by ligand (Fig. 4) correlated with IL-2-mediated enhancement of EC proliferation (Fig. 1). Third, binding of ${ }^{125} \mathrm{I}-\mathrm{IL}-2$ at $37^{\circ} \mathrm{C}$ to ECs pretreated with IFN- $\alpha$ resulted in internalization of the tracer: specifically cell-associated ${ }^{125} \mathrm{I}-\mathrm{IL}-2$ was present on the cell surface (eluted in the presence of acidic buffer) and in an internalized pool (released by dissolution of the cells with detergent after removal of surface-bound pool) (data not shown). Resistance of the pool of internalized ${ }^{125} \mathrm{I}$ IL-2 to elution with acidic buffer was not due to irreversible binding to a cell surface structure, as it was not released by exposure of cultures to trypsin, and no higher molecular weight complex of ligand with another protein was evident on SDSPAGE. Thus, it was concluded that this pool of cell-associated ${ }^{125}$ I-IL-2 on IFN- $\alpha$-treated ECs was intracellular. When heatinactivated IFN- $\alpha$ was substituted for the native molecule, only very small amounts of endocytosed ${ }^{125}$ I-IL-2 were observed

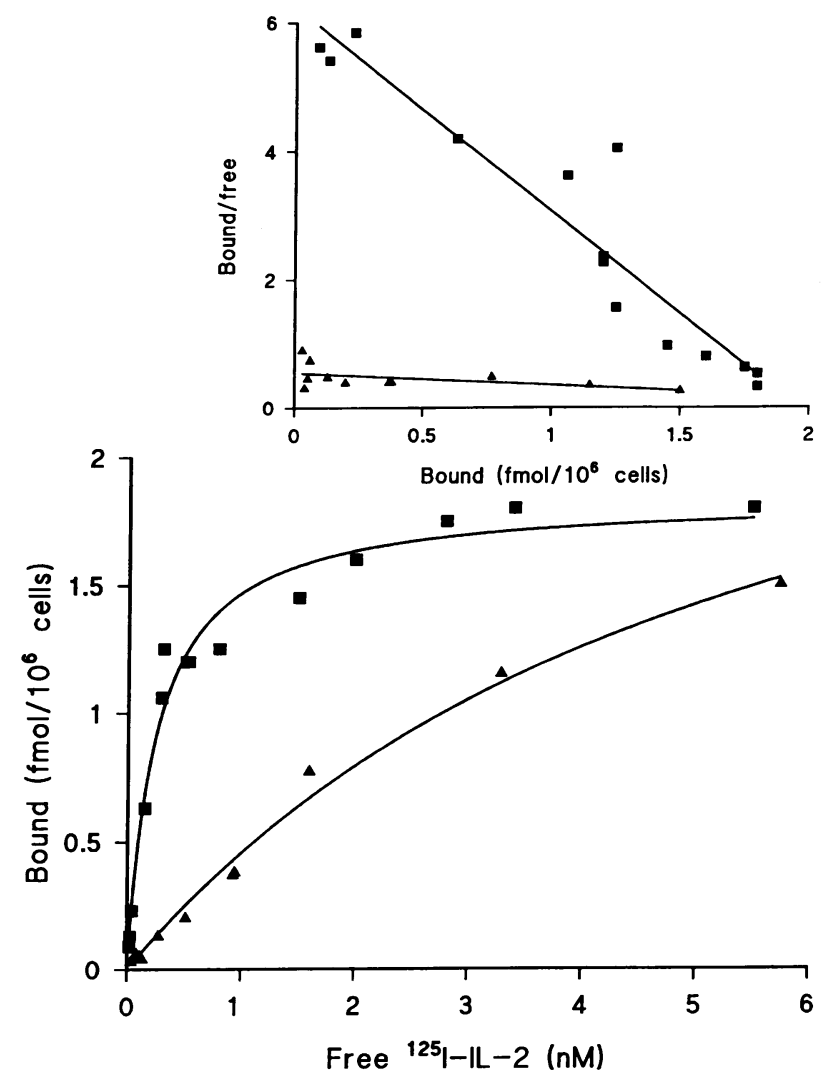

Figure 4. Binding of ${ }^{125} \mathrm{I}-\mathrm{IL}-2$ to EC: effect of IFN- $\alpha$. EC cultures, preincubated in control medium alone $(\Delta)$ or control medium supplemented with IFN- $\alpha(0.5 \mathrm{nM} ; \approx)$ for $24 \mathrm{~h}$, were exposed to ${ }^{125} \mathrm{I}-\mathrm{IL}-2$ alone (total binding) or ${ }^{125} \mathrm{I}-\mathrm{IL}-2$ in the presence of excess unlabeled IL-2 (nonspecific binding). The internalization/binding assay was performed as described in the text, and data was fit to a one-site model by nonlinear least-squares analysis: $K_{\mathrm{d}} 6.1 \pm 0.3 \mathrm{nM}$ and 1,600 binding sites for unstimulated cultures, and $K_{\mathrm{d}} 260 \pm 30 \mathrm{pM}$ and 1,800 binding sites for IFN- $\alpha$-treated cultures. Values shown represent the mean of triplicate determinations at each point (SEM was always $<15 \%)$. Inset: Scatchard analysis of the same data.

Table I. Binding of ${ }^{125} I-I L-2$ to ECs: Effect of Anti-p55 mAb*

\begin{tabular}{llc}
\hline Stimulus & mAb added & $\begin{array}{c}\text { Cell-associated } \\
\text { 125I-IL-2 bound }\end{array}$ \\
\hline & & fmole/well \\
Nil & anti-p55 IgG & $0.38 \pm 0.04$ \\
Nil & control IgG & $1.90 \pm 0.21$ \\
IFN- $\alpha$ & anti-p55 IgG & $0.55 \pm 0.11$ \\
IFN- $\alpha$ & control IgG & $3.33 \pm 0.33$ \\
\hline
\end{tabular}

* EC cultures were preincubated with either control medium alone (Nil) or control medium supplemented with $0.5 \mathrm{nM}$ IFN- $\alpha$ for $24 \mathrm{~h}$. Then, cultures were washed, and either anti-p $55 \mathrm{mAb}$ or an irrelevant $\mathrm{mAb}$ of the same subtype was added for $30 \mathrm{~min}$ at room temperature. Finally, ${ }^{125} \mathrm{I}-\mathrm{IL}-2(1 \mathrm{nM})$ alone (total binding) or ${ }^{125} \mathrm{I}-\mathrm{IL}-2$ in the presence of excess unlabeled IL-2 (nonspecific binding) was added for $40 \mathrm{~min}$ at $37^{\circ} \mathrm{C}$. Cultures were then washed to remove unbound ${ }^{125} \mathrm{I}-\mathrm{IL}-2$, and surface-associated radioactivity was eluted, as described in the text. Specifically (total minus nonspecific) cell-associated ${ }^{125} \mathrm{I}-$ IL-2 is shown (mean \pm SD of triplicate determinations). The results of one experiment out of three performed are shown. 
Table II. Effect of Anti-IL-2 Receptor p55 Chain IgG on IL-2-induced Proliferation of ECs Treated with IFN- $\alpha^{*}$

\begin{tabular}{lccc}
\hline & \multicolumn{3}{c}{$\left[{ }^{3} \mathrm{H}\right]$ thymidine in the presence of } \\
\cline { 2 - 4 } \multicolumn{1}{c}{ Stimulus } & Medium & $\begin{array}{c}\text { Anti-p55 } \\
\text { IgG }\end{array}$ & $\begin{array}{c}\text { Control } \\
\text { Ig }\end{array}$ \\
\hline & & $c p m$ & \\
Nil & 11,150 & 13,450 & 12,300 \\
rIL-2 $(10 \mathrm{ng} / \mathrm{ml})$ & 44,667 & 7,853 & 45,672
\end{tabular}

* EC cultures were preincubated with control medium supplemented with IFN- $\alpha(0.5 \mathrm{nM})$ for $24 \mathrm{~h}$, cultures were washed, and then IL-2 $(0.5 \mathrm{nM})$ was added either alone (medium), or in the presence of anti-p55 $\operatorname{IgG}(10 \mu \mathrm{g} / \mathrm{ml})$, or of control $\operatorname{IgG}(10 \mu \mathrm{g} / \mathrm{ml})$. Data shown (mean of triplicate determinations; SD was always $<10 \%$ ) are the results of one experiment out of three performed.

(data not shown). Experiments under the same conditions with acetylated LDL substituted for ${ }^{125}$ I-IL-2 did not demonstrate increased EC uptake (data not shown). This suggests that enhanced receptor-mediated endocytosis of IL-2 on IFN$\alpha$-treated ECs was not a general finding for all EC receptor-ligand interactions.

Effect of IFN- $\alpha$ on expression of endothelial $I L-2$ receptor p55 and p70 chains. The high-affinity IL-2 receptor is a complex, multichain structure, which, in lymphoid cells, is composed of at least two cytokine-binding molecules, the p70 chain and the p55 chain, as well as a number of other molecules that become noncovalently associated after interaction with the ligand $(10,12)$. The shift in the affinity of IL-2 binding to ECs following preincubation with IFN- $\alpha$ suggested that changes in expression of EC IL-2 receptor chains might be occurring. To test this hypothesis, EC cultures were biosynthetically labeled, and lysates were immunoprecipitated with murine mAbs to p70 or p55. SDS-PAGE analysis of immunoprecipitates with anti-p70 mAb showed a 70-kD protein only in lysates of ECs exposed to IFN- $\alpha$, but not in untreated controls (Fig. $5 \mathrm{~A}$, lanes

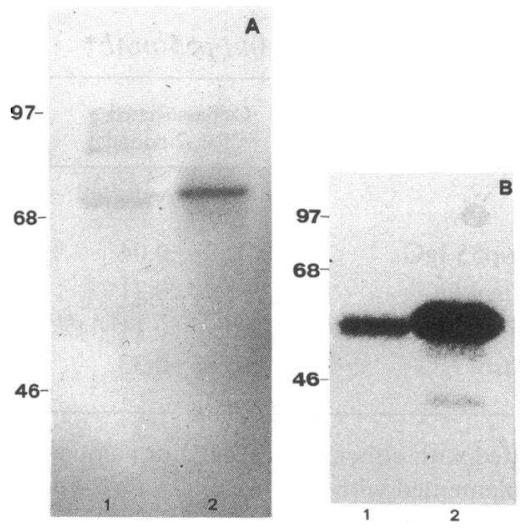

Figure 5. SDS-PAGE analysis of IL-2 receptor p55 and p70 chains expression by cultured ECs: effect of IFN- $\alpha$. Preconfluent ECs maintained for $48 \mathrm{~h}$ in control medium, were exposed for $4 \mathrm{~h}$ to either fresh methionine- and cysteine-free control medium containing $\left[{ }^{35}\right.$ S $]$ methionine and $\left[{ }^{35} \mathrm{~S}\right]$ cysteine and no cytokines, or with the same medium with

IFN- $\alpha(0.5 \mathrm{nM})$. Cultures were lysed and subjected to immunoprecipitation with mAbs to $\mathrm{p} 70(A)$ or to $\mathrm{p} 55(B)$. Lysates were immunoprecipitated with the same amount of $\mathrm{mAb}$ (see text for details of procedure). ( $A$ ) Lane 1, quiescent ECs; lane 2, IFN- $\alpha$-treated cells. ( $B)$ Lane 1 , quiescent ECs; lane 2, IFN- $\alpha$-treated cells. The migration of standard proteins, run simultaneously, is indicated by the marker bars in kilodaltons.
1 and 2). In contrast, in immunoprecipitates with anti-p55 $\mathrm{mAb}$, a 55-kD protein was detected in lysates of quiescent cultured ECs, and exposure to IFN- $\alpha$ enhanced its expression (Fig. $5 \mathrm{~B}$, lanes 1 and 2 ). Note that an irrelevant murine $\mathrm{mAb}$ did not precipitate either band migrating in the $50-80-\mathrm{kD}$ molecular mass range (data not shown).

Association of $I L-2$ receptor $p 55$ and $p 70$ chains with endothelium in vivo. In view of the EC expression of $\mathrm{p} 55$ and $\mathrm{p} 70$ observed in cell culture, we investigated whether IL- 2 receptors could be associated with endothelium in vivo. Our attention was focused on rheumatoid arthritis, a situation in which angiogenesis in the joint space occurs in the context of an abundance of activated lymphoid cells likely to be producing cytokines (7). Indirect immunofluorescence of synovial tissues from a patient with rheumatoid arthritis with mAbs to p55 and p70 antigens demonstrated a focal distribution in the small blood vessels (Fig. 6, $A$ and $C$ ). No p55 or p70 antigen could be detected in joint tissue from normal individuals or a patient with osteoarthritis (data not shown). Although the latter observation would appear to conflict with the constitutive expression of p55 seen in cultured ECs above, it is possible that this represents another change in EC phenotype which occurs when umbilical vein ECs adapt to tissue culture.

Effect of IFN- $\alpha$ and IL-2 on EC synthesis, release, and internalization of $b F G F$. The effectiveness of IL- 2 and IFN- $\alpha$ in stimulating EC growth, which was similar in magnitude to the effect of bFGF, suggested the possibility that these cytokines might alter expression/availability of EC bFGF. To test this hypothesis, EC monolayers were pulsed with IFN- $\alpha$ for $18 \mathrm{~h}$, and then proteins were biosynthetically labeled in the presence/absence of IL-2 for $4 \mathrm{~h}$. Analysis of cell lysates precipitated with monospecific polyclonal IgG raised to bFGF demonstrated a band with $M_{\mathrm{r}} \approx 17 \mathrm{kD}$ in unstimulated ECs (Fig. 7, left, lane 3 ). This band disappeared on addition of excess unlabeled bFGF during incubation with the primary antibody (Fig. 7 , middle, lanes 1 and 2 ). Several other, more slowly migrating bands, immunoprecipitated with anti-bFGF antibodies from ECs, also disappeared on addition of unlabeled bFGF, consistent with previous reports of higher $M_{\mathrm{r}}$ forms of bFGF in endothelium (13). Taken together, these data indicate that the metabolically labeled protein of $M_{\mathrm{r}} \approx 17 \mathrm{kD}$, immunoreactive with anti-bFGF antibodies, was most likely EC-derived bFGF. Levels of metabolically labeled bFGF in cell lysates were increased on exposure of cultures to IFN- $\alpha$ (Fig. 7, left, lane 2).

In contrast to the rise in bFGF levels induced by IFN- $\alpha$, subsequent addition of IL-2 led to a decrease in immunoprecipitable bFGF in cell lysates (Fig. 7, left, lane 1). The apparent reason for this decrease in intracellular bFGF was evident from SDS-PAGE analysis of culture supernatants from IFN- $\alpha /$ IL2-stimulated ECs (Fig. 7, right): although bFGF was undetectable in medium from quiescent cultures (Fig. 7, right, lane 1), and was barely detectable in IFN- $\alpha$-treated cells (Fig. 7, right, lane 2), considerable amounts of bFGF were present in the medium from ECs exposed sequentially to IFN- $\alpha$ and IL-2 (Fig. 7, right, lane 3 ). The likely identity of metabolically labeled protein with $M_{\mathrm{r}} \approx 17 \mathrm{kD}$ in the supernatant of IFN- $\alpha$ / IL-2-treated ECs with bFGF was emphasized by its disappearance in the presence of excess unlabeled bFGF (data not shown ).

These data support the hypothesis that IFN- $\alpha$ and IL-2 drive EC proliferation via enhancing EC synthesis and release 

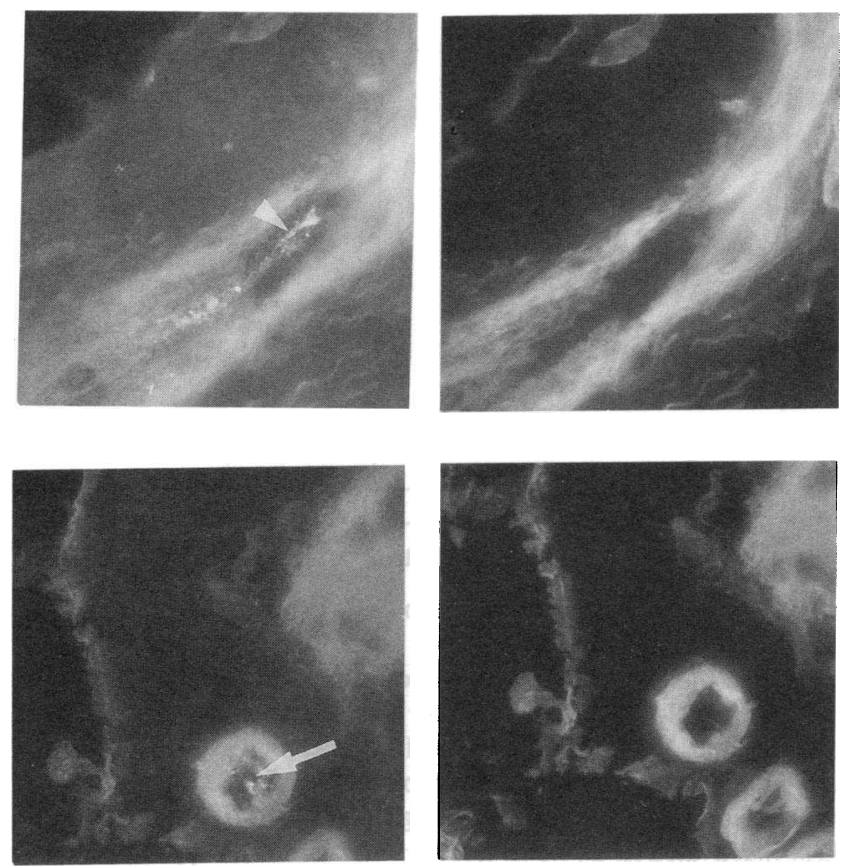

Figure 6. Expression of IL-2 receptor chains in rheumatoid synovium. $\mathrm{p} 55(A)$ and $\mathrm{p} 70(C)$ antigen expression was detected by indirect immunofluorescence, using FITC-conjugated antibodies, in frozen tissue sections prepared from synovial biopsies. Sections were counterstained with a rhodamine isothiocyanate (TRIC)-conjugated rabbit anti-human basement membrane antiserum. $(A)$ p 55 is expressed along the endothelium (arrow) of an arteriole. $(B)$ The same field as in $A$ is viewed with a rhodamine filter system to localize the basement membrane of the arteriolar wall. $(C)$ p70 is expressed by endothelium (arrow) of an arteriole. (D) The same field as in $C$ is viewed with a rhodamine filter system to localize the arteriolar wall. Magnification, $\times 400$.

of bFGF. To test this directly, ECs were stimulated with IFN- $\alpha$ and IL-2 in the presence of neutralizing anti-bFGF IgG ( Table III). IFN- $\alpha$ /IL-2-enhanced proliferation was blocked by $50-$

Table III. Effect of Anti-bFGF Antibodies on IL-2-induced Proliferation of ECs Treated with IFN- $\alpha^{*}$

\begin{tabular}{lccc}
\hline & \multicolumn{3}{c}{$\left[{ }^{3} \mathrm{H}\right]$ thymidine in the presence of } \\
\cline { 2 - 4 } \multicolumn{1}{c}{ Stimulus } & Medium & $\begin{array}{c}\text { Anti-bFGF } \\
\text { lgG }\end{array}$ & $\begin{array}{c}\text { Control } \\
\text { IgG }\end{array}$ \\
\hline & & $c p m$ & \\
Nil & 6,988 & 5,450 & 7,300 \\
rIL-2 $(50 \mathrm{pM})$ & 18,840 & 9,100 & 19,780 \\
rIL-2 $(0.5 \mathrm{nM})$ & 30,450 & 13,280 & 29,980 \\
& & & \\
\hline
\end{tabular}

* Preconfluent ECs were maintained in control medium for $48 \mathrm{~h}$, then IFN- $\alpha(0.5 \mathrm{nM})$ was added for $24 \mathrm{~h}$, followed by either no further addition (Nil) or the addition of IL-2 ( $50 \mathrm{pM}$ or $0.5 \mathrm{nM}$ ), alone (medium) or in the presence of rabbit anti-bFGF IgG $(10 \mu \mathrm{g} / \mathrm{ml})$, or control rabbit $\mathrm{IgG}(10 \mu \mathrm{g} / \mathrm{ml})$ for $48 \mathrm{~h}$. [ ${ }^{3} \mathrm{H}$ ]thymidine incorporation was determined as described in the text. Data shown are the means of triplicate determinations (SD was always $<10 \%$ ). One experiment representative of three performed is shown.
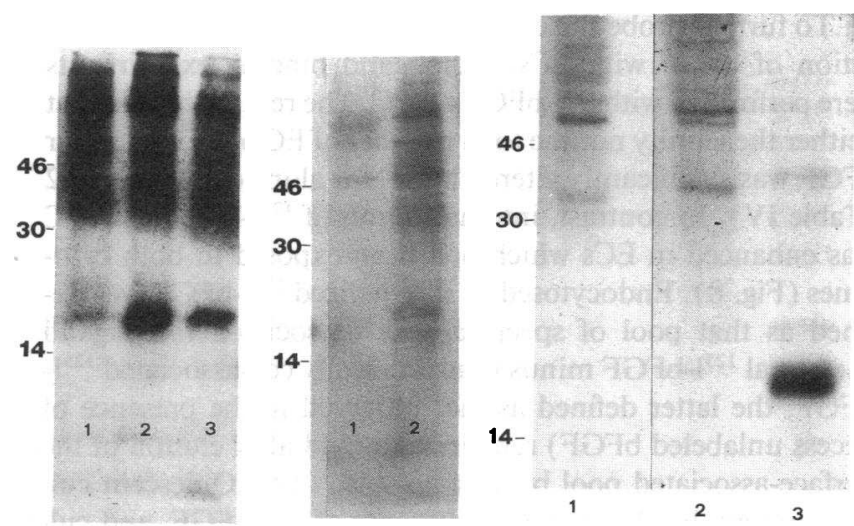

Figure 7. SDS-PAGE analysis of bFGF synthesis and release by cultured ECs: effect of IFN $-\alpha$ and IL-2. EC monolayers were maintained in control medium for $48 \mathrm{~h}$, stimulated or not with IFN- $\alpha(0.5 \mathrm{nM})$ for $18 \mathrm{~h}$, washed, and then cultured in methionine- and cysteine-free MEM containing $\left[{ }^{35} S\right]$ methionine and $\left[{ }^{35} S\right]$ cysteine for an additional $6 \mathrm{~h}$ in the presence or absence of IL-2 $(0.5 \mathrm{nM})$. Immunoprecipitation was performed on cell lysates (left and middle panels) and culture supernatants (right panel), using rabbit anti-bFGF $\operatorname{IgG}(5 \mu \mathrm{g} / \mathrm{ml})$. Where indicated, bFGF ( $35 \mu \mathrm{g} / \mathrm{ml})$ was added to samples during the incubation with the anti-bFGF IgG. Details of procedure are described in the text. Left (cell lysates): lane 1, quiescent ECs, no cytokines added; lane 2, ECs exposed to IFN- $\alpha$; lane 3, ECs exposed to IFN- $\alpha$ and IL-2. Middle: lysates of IFN- $\alpha$-treated ECs immunoprecipitated in the presence (lane 1 ) or in the absence (lane 2) of excess unlabeled bFGF. Right: (supernatants): lane 1, quiescent ECs, no cytokines added; lane 2, ECs exposed to IFN- $\alpha$; lane 3, ECs exposed to IFN- $\alpha$ and IL-2.

$60 \%$ by antibody to bFGF ( $10 \mu \mathrm{g} / \mathrm{ml})$, whereas nonimmune IgG was ineffective. Although higher concentrations of antibFGF antibodies $(50 \mu \mathrm{g} / \mathrm{ml})$ completely blocked IFN- $\alpha / \mathrm{IL}-2-$ mediated stimulation of EC proliferation (and preimmune IgG at the same concentration was without effect), these levels of anti-bFGF IgG resulted in a looser attachment of ECs to the growth substrate, leading to a variable cell loss during washing procedures and less reproducible results.

Table IV. Parameters of ${ }^{125} I-b F G F$ Binding to ECs Exposed to IFN- $\alpha$ and $I L-2 *$

\begin{tabular}{lcl}
\hline \multicolumn{1}{c}{ Stimulus } & $K_{\mathrm{d}}$ & Binding sites per cell \\
\hline & $p M$ & \\
Nil & $80 \pm 9$ & $7,702 \pm 1,890$ \\
IFN- $\alpha$ & $64 \pm 8$ & $6,862 \pm 943$ \\
IFN- $\alpha+$ IL-2 & $51 \pm 7$ & $8,937 \pm 1,914$ \\
\hline
\end{tabular}

* Preconfluent ECs were maintained in control medium for $48 \mathrm{~h}$, and were then exposed to control medium containing either no further additions (Nil), IFN- $\alpha(0.5 \mathrm{nM})$, or IFN- $\alpha+$ IL-2 (each at $0.5 \mathrm{nM}$ ) for $24 \mathrm{~h}$. Cultures were then washed and radioligand binding assays were performed at $4^{\circ} \mathrm{C}$ with ${ }^{125} \mathrm{I}-\mathrm{bFGF}$ in the presence/absence of excess unlabeled bFGF, as described in the text. Specifically bound ${ }^{125} \mathrm{I}$ bFGF versus free/added ${ }^{125} \mathrm{I}-\mathrm{bFGF}$ was analyzed by nonlinear least squares analysis using a one-site model. Binding parameters are shown above for each of the three conditions. 
To further probe the effect of IFN- $\alpha$ and IL-2 on the interaction of bFGF with ECs, radioligand binding experiments were performed with ${ }^{125} \mathrm{I}-\mathrm{bFGF}$ at $4^{\circ} \mathrm{C}$. The results showed that neither the affinity nor the total number of EC binding sites for bFGF was significantly altered by IFN- $\alpha$ alone or IFN- $\alpha /$ IL-2 (Table IV). In contrast, internalization of ${ }^{125} \mathrm{I}-\mathrm{bFGF}$ at $37^{\circ} \mathrm{C}$ was enhanced in ECs which had been exposed to both cytokines (Fig. 8). Endocytosed or internalized ${ }^{125}$ I-bFGF was defined as that pool of specifically cell-associated radioligand (i.e., total ${ }^{125} \mathrm{I}-\mathrm{bFGF}$ minus nonspecifically cell-associated ${ }^{125} \mathrm{I}$ bFGF, the latter defined as that observed in the presence of excess unlabeled bFGF) remaining bound after elution of the surface-associated pool by an acid wash (14). Quiescent cultures internalized only small amounts of ${ }^{125} \mathrm{I}-\mathrm{bFGF}$, and cultures preincubated with either IFN- $\alpha$ or IL- 2 alone showed uptake of only slightly greater amounts of bFGF. However, ECs exposed to both cytokines internalized enhanced amounts of ${ }^{125}$ I-bFGF (Fig. 8). Control experiments under the same conditions with acetylated LDL did not demonstrate increased cellular uptake, suggesting that enhanced receptor-mediated endocytosis of bFGF by ECs treated with IFN- $\alpha$ /IL-2 was not a general finding for all EC receptor-ligand interaction (data not shown).

\section{Discussion}

The findings reported here indicate that ECs exposed to IFN- $\alpha$ become responsive to the mitogenic effects of IL-2. Although prior studies have described a direct effect of IL-2 alone on cultured ECs, in terms of prostacyclin release, increased permeability, and, under certain circumstances, also cell proliferation (15-17), in our studies IL-2-mediated stimulation of EC growth required endothelial activation, brought about by IFN$\alpha$. Consistent with this interpretation, IFN- $\alpha$-treated ECs demonstrated a close correlation between concentrations of IL-2 which induced EC proliferation and those which resulted in occupancy of endothelial IL-2 binding sites, and internalization of EC surface-bound IL-2 occurred only after exposure to IFN- $\alpha$. The means through which IFN- $\alpha$ exerted its EC effects in this context appeared to involve, at least in part, enhanced expression of the p55 chain (whose constitutive expression by cultured ECs had been previously reported [17]) and induction of the p70 chain of the IL-2 receptor, allowing the cells to respond to added IL- 2 by an as yet undefined signal transduction pathway that eventuated in release of bFGF. The results of immunohistologic studies of synovial tissues from rheumatoid joints, which displayed vascular staining for p55 and p70, support the observations in cell culture. Although these data do not prove that ECs synthesize p55 and p70 in vivo, it lends support to the concept that $\mathrm{p} 55$ and $\mathrm{p} 70$ can have a vascular distribution, and, potentially, vascular expression.

EC proliferation in cultures pretreated with IFN- $\alpha$ appeared to reflect several underlying mechanisms, principally involving the synthesis and release of bFGF. IFN- $\alpha$ increased intracellular levels of bFGF, but did not lead to detectable bFGF in culture supernatants. Addition of IL-2 to IFN- $\alpha-$ stimulated EC cultures led to release of bFGF into the medium, and was followed by stimulation of cell growth. In that bFGF is a polypeptide which lacks a signal sequence (5), this raises the intriguing question of whether its presence in supernatants was

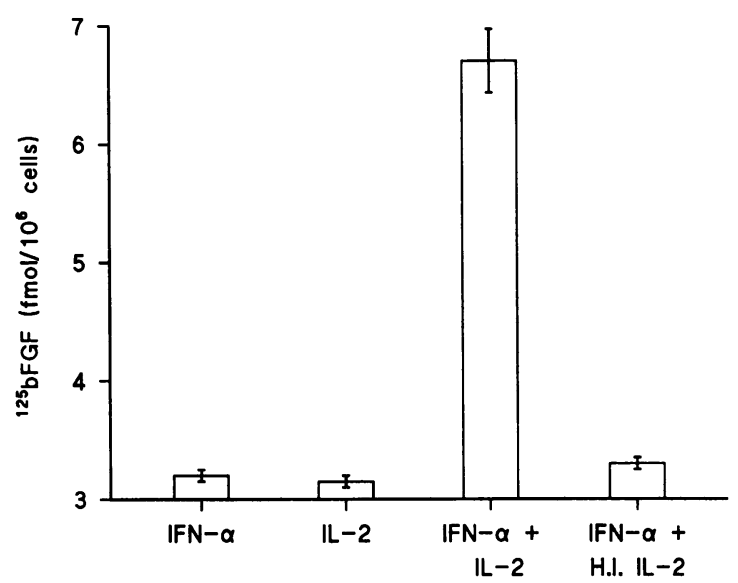

Figure 8. Internalization of ${ }^{125}$ I-bFGF by ECs exposed to IFN- $\alpha$. Cultured ECs were maintained for $48 \mathrm{~h}$ in control medium, and then incubated in the same medium with no further addition or supplemented with IFN- $\alpha$ alone $(0.5 \mathrm{nM})$ for $24 \mathrm{~h}$. Cells were then washed and endogenous FGF bound to cell surface receptor was eluted with acidic buffer. Cultures were then incubated for $2 \mathrm{~h}$ at $37^{\circ} \mathrm{C}$ with no further additions (IFN- $\alpha$ ) or containing IL-2 (0.5 nM; IFN- $\alpha+I L-2)$ or heat-inactivated IL-2 $(0.5 \mathrm{nM} ; I F N-\alpha+H . I . I L-2)$, supplemented with ${ }^{125}$ I-bFGF alone $(0.5 \mathrm{nM})$ or in the presence of a 200 -fold molar excess of unlabeled bFGF. The bar designed IL-2 denotes cultures exposed to control medium alone (i.e., no IFN- $\alpha$ ) in the first phase and IL-2 $(0.5 \mathrm{nM})$ in the second phase. After the incubation period, cultures were washed to remove unbound ligand, cell-surface associated ligand was eluted by exposure to acidic buffer, and the remaining cell-associated radioactivity, the internalized pool, was released by dissolving the cultures in detergent-containing buffer. Data shown are specifically internalized ${ }^{125}$ I-bFGF (mean \pm SEM of triplicate determinations) which was defined as total internalized ${ }^{125} \mathrm{I}$ bFGF (that observed in cultures incubated with the tracer alone) minus non-specifically internalized ${ }^{125} \mathrm{I}-\mathrm{bFGF}$ (that observed in cultures incubated with the tracer in the presence of excess unlabelled ligand).

the result of an active process of secretion or else of passive discharge from damaged cells; however, in EC cultures stimulated with IFN- $\alpha$ /IL- 2 we could observe no increase in cellular trypan blue uptake, no increase in release of $\mathrm{LDH}$, and no evidence of increased numbers of floating/detached cells. Furthermore, lysates of many more endothelial cells than were present in our experiments would be required to obtain the proliferative effects exhibited by cultures exposed to IFN- $\alpha /$ IL2 (data not shown). In support of this concept, secretion of bFGF has recently been documented in other instances in which cellular toxicity appears to be unlikely; Kandel and colleagues demonstrated bFGF release from fibrosarcoma cells which promoted neoangiogenesis in a transgenic mouse model (18), and Mignatti and colleagues showed that migration of single, isolated EC, mediated by autocrine bFGF, could be blocked by neutralizing antibodies (19). In this context, other polypeptides which lack a signal peptide, including IL-1 $\beta(20)$, thioredoxin (21), prothymosin $\alpha$ (22), anchorin CII (23), a platelet-derived EC growth factor (24), are also known to be released from cells in the absence of overt changes in cell viability, though the detailed mechanisms involved have yet to be elucidated (25). Once released into culture supernatants, it has been amply demonstrated that bFGF effectively enhances cell 
growth, as 3T3 cells transfected with a construct of bFGF containing a signal peptide resulted in efficient export of growth factor from the cell and potent stimulation of cell growth (26).

Stimulated cultured endothelium expressing the p55 and p70 chains of the IL-2 receptor bound the ligand with a $K_{\mathrm{d}}$ $\approx 260 \mathrm{pM}$. Although this is considerably higher-affinity binding than that observed for IL-2 binding to unstimulated cultured ECs, the latter cells expressing only p55, it is lower than the affinity for IL-2 displayed by the receptor on activated lymphoid cells; however, in the IL-2 system, the affinity per se is not critical. In fact, $3 \mathrm{~T} 3$ fibroblasts co-transfected with cDNAs encoding both the p55 and p70 chains of the receptor express IL-2 binding sites which have a $K_{\mathrm{d}} \approx 60 \mathrm{pM}$ and which mediate internalization of cell-bound ligand, but do not transmit any growth signal (27); on the other hand, oligodendroglioma cells transfected with a p70-encoding cDNA can bind IL-2 with intermediate-affinity sites $(\approx 2 \mathrm{nM})$, but are sensitive to the growth-promoting effect of the cytokine (28). Indeed, the p70 chain, upon binding to IL-2, associates with at least a third molecule (in lymphoid cells, the tyrosine kinase p56 $6^{\text {lck }}[12]$ ), that appears to participate in delivering the proliferative stimulus and may enhance the affinity of cytokine binding to the receptor (12). Intracellular signal transduction mechanisms activated by IL- 2 in endothelium are likely to be peculiar, with the final proliferative stimulus arising from $\mathrm{bFGF/FGF} \mathrm{recep-}$ tor interaction.

Further studies will be required to assess the full spectrum of EC properties modulated by IFN- $\alpha /$ IL-2, but from the results thus far, it is likely that the effector mechanisms activated will provide insights into the pathogenesis of vascular reactions in certain immune/inflammatory settings. For example, perturbation of EC properties may underlie the observation that IFN- $\alpha$ and IL- 2 together induce marked hemorrhagic and exudative lesions in an experimental model of Goodpasture's pneumonitis (16). In another context, IFN- $\alpha /$ IL-2-induced release of bFGF can elicit EC production of proteases (29), potentially facilitating blood vessel invasion as occurs in the rheumatoid pannus. On the other hand, our results raise many questions, such as the reason for the difference between the effect of IFN- $\alpha$ to cause regression of abnormal vascular structures (i.e., hemangiomas) (30) versus the angiogenic potential of this cytokine in the rabbit cornea model and its mitogenic properties for cultured endothelium. The neoplastic nature of hemangioma cells may account for this discrepancy; a relevant example of functional differences between neoplastic and normal endothelium is the proliferation of Kaposi's sarcoma cells in response to IL-1 (31), which acts as a growth-inhibitory cytokine for normal ECs $(9,32)$. Future studies will be required to fully elucidate the phenotype of the IFN- $\alpha$ /IL-2-stimulated endothelial cell.

\section{Acknowledgments}

We thank Dr. F. Bertolero (Farmitalia, Milan, Italy) for providing rbFGF.

This work was supported by the National Research Council, Italy (grant \#91.00340.PF40), the Italian Association for Cancer Research (AIRC), the U.S. Public Health Service (grants HL-42507, HL-34625, HL-42833, and HL-21006), the Council for Tobacco Research, and Stony-Wold Foundation. D. Stern completed this work during the ten- ure of a Genentech-Established Investigator Award from the American Heart Association.

\section{References}

1. Folkman, J., K. Watson, D. Ingber, and D. Hanahan. 1989. Induction of angiogenesis during the transition from hyperplasia to neoplasia. Nature (Lond.). 339:58-61.

2. Klagsbrun, M., and P. A. D'Amore. 1991. Regulators of angiogenesis. Annu. Rev. Physiol. 53:217-239.

3. Folkman, J., and M. Klagsbrun. 1987. Angiogenic factors. Science (Wash DC). 235:442-447.

4. Gospodarowicz, D., J. Cheng, M. Luiu, A. Baird, and P. Bohlen. 1984. Isolation of brain fibroblast growth factor by heparin-Sepharose affinity chromatography: identity with pituitary fibroblast growth factor. Proc. Natl. Acad. Sci. USA. 81:6963-6967.

5. Burgess, W. H., and T. Maciag. 1989. The heparin-binding (fibroblast) growth factor family of proteins. Annu. Rev. Biochem. 58:575-606.

6. Gospodarowicz, D. 1991. Biological activities of fibroblast growth factors. Ann. N.Y. Acad. Sci. 638:1-8.

7. Harris, E. D., Jr. 1990. Rheumatoid arthritis. Pathophysiology and implications for therapy. N. Engl. J. Med. 322:1277-1288.

8. Plouet, J., and D. Gospodarowicz. 1989. Transforming growth factor beta1 positively modulates the bioactivity of fibroblast growth factor on corneal endothelial cells. J. Cell Physiol. 141:392-399.

9. Cozzolino, F., M. Torcia, D. Aldinucci, M. Ziche, F. Almerigogna, D. Bani, and D. M. Stern. 1990. Interleukin 1 is an autocrine regulator of human endothelial cell growth. Proc. Natl. Acad. Sci. USA. 87:6487-6491.

10. Hatakeyama, M., M. Tsudo, S. Minamoto, T. Kono, T. Doi, T. Miyata, M. Miyasaka, and T. Taniguchi. 1989. Interleukin-2 receptor beta chain gene: generation of three receptor forms by cloned human alpha and beta chain cDNA's. Science (Wash. DC). 244:551-556.

11. Ziche, M., G. Alessandrini, and P. M. Gullino. 1989. Gangliosides promote the angiogenic response. Lab. Invest. 61:629-634.

12. Hatakeyama, M., T. Kono, N. Kobayashi, A. Kawahara, S. D. Levin, R. M. Perlmutter, and T. Taniguchi. 1991. Interaction of the IL-2 receptor with the $s r c$-family kinase p $56^{\text {kck: }}$ identification of novel intermolecular association. Science (Wash. DC). 252:1523-1528.

13. Burgess, W. H., J. Bizik, T. Mehlman, N. Quarto, and D. B. Rifkin. 1991. Direct evidence for methylation of arginine residues in high molecular weight forms of basic fibroblast growth factor. Cell Regul. 2:87-93.

14. Fujii, M., K. Sugamura, K. Sano, M. Nakai, K. Sugita, and Y. Hinuma 1986. High-affinity receptor-mediated internalization and degradation of interleukin 2 in human T cells. J. Exp. Med. 163:550-562.

15. Frasier-Scott, K., H. Hatzakis, D. Seong, C. M. Jones, and K. K. Wu. 1988. Influence of natural and recombinant interleukin 2 on endothelial cell arachidonate metabolism: induction of de novo synthesis of prostaglandin $\mathrm{H}$ synthase. J. Clin. Invest. 82:1877-1883.

16. Queluz, T. H., I. Pawloski, M. J. Brunda, J. R. Brentjens, A. O. Vladutiu, and G. Andres. 1990. Pathogenesis of an experimental model of Goodpasture's hemorragic pneumonitis. J. Clin. Invest. 85:1507-1515.

17. Hicks, C., M. A. Cooley, and R. Penny. 1991. Investigation of interleukin 2 receptors on human endothelial cells. Growth Factors. 5:201-208.

18. Kandel, J., E. Bossy-Wetzel, F. Radvanyi, M. Klagsbrun, J. Folkman, and D. Hanahan. 1991. Neovascularization is associated with a switch to the export of bFGF in the multistep development of fibrosarcoma. Cell. 66:1095-1104.

19. Mignatti, P., T. Morimoto, and D. B. Rifkin. 1991. Basic fibroblast growth factor released by single, isolated cells stimulates their migration in an autocrine manner. Proc. Natl. Acad. Sci. USA. 88:11007-11011.

20. Rubartelli, A., F. Cozzolino, M. Talio, and R. Sitia. 1990. A novel secretory pathway for interleukin-1 $\beta$, a protein lacking a signal sequence. $E M B O(E u r$. Mol. Biol. Organ.) J. 9:1503-1510.

21. Tagaya, Y., Y. Maeda, A. Mitsui, N. Kondo, H. Matsui, J. Hamuro, N. Brown, K. Arai, T. Yokota, H. Wakasugi, et al. 1989. ATL-derived factor (ADF), an IL-2 receptor/Tac inducer homologous to thioredoxin: possible involvement of dithiol-reduction in the IL-2 receptor induction. EMBO (Eur. Mol. Biol. Organ.) J. 8:757-764.

22. Eschenfeldt, W. H., R. E. Manrow, M. S. Krug, and S. L. Berger. 1989. Isolation and partial sequencing of the human prothymosin alpha gene family: evidence against export of the gene products. J. Biol. Chem. 264:7546-7555.

23. Pfäflle, M., F. Ruggiero, H. Hofmann, M. P. Fernàndez, O. Selmin, Y. Yamada, R. Garrone, and K. von der Mark. 1988. Biosynthesis, secretion and extracellular localization of anchorin CII, a collagen-binding protein of the calpactin family. EMBO (Eur. Mol. Biol. Organ.) J. 7:2335-2342.

24. Usuki, K., N. E. Heldin, K. Miyazono, F. Ishikawa, F. Takaku, B. Westermark, and C. H. Heldin. 1989. Production of platelet-derived endothelial cell 
growth factor by normal and transformed human cells in culture. Proc. Natl. Acad. Sci. USA. 86:7427-7431.

25. Kuchler, K., and J. Thorner. 1990. Membrane translocation of proteins without hydrophobic signal peptide. Curr. Opin. Cell Biol. 2:617-624.

26. Rogelj, S., R. A. Weinberg, P. Fanning, and M. Klagsbrun. 1988. Basic fibroblast growth factor fused to a signal peptide transforms cells. Nature (Lond.). 331:173-175.

27. Tsudo, M., H. Karasuyama, F. Kitamura, T. Tanaka, S. Kubo, Y. Yamamura, T. Tamatani, M. Hatakeyama, T. Taniguchi, and M. Miyasaka. 1990. The IL-2 receptor beta-chain (p70). Ligand binding ability of the cDNA-encoding membrane and secreted forms. J. Immunol. 145:599-606.

28. Okamoto, Y., S. Minamoto, K. Shimizu, H. Mogami, and T. Taniguchi. 1990. Interleukin 2 receptor beta chain expressed in an oligodendroglioma line binds interleukin 2 and delivers growth signal. Proc. Natl. Acad. Sci. USA. 87:6584-6588.
29. Tsuboi, R., Y. Sato, and D. B. Rifkin. 1990. Correlation of cell migration, cell invasion, receptor number, proteinase production, and basic fibroblast growth factor levels in endothelial cells. J. Cell Biol. 110:511-517.

30. Ezekowitz, R. A. B., J. B. Mulliken, and J. Folkman. 1992. Interferon alpha-2a therapy for life-threatening hemangiomas of infancy. N. Engl. J. Med. 326:1456-1463.

31. Ensoli, B., S. Nakamura, S. Z. Salahuddin, P. Biberfeld, L. Larsson, B. Beaver, F. Wong-Staal, and R. C. Gallo. 1989. AIDS-Kaposi's sarcoma-derived cells express cytokines with autocrine and paracrine growth effects. Science (Wash. DC). 243:223-226.

32. Norioka, K., M. Hara, A. Kitani, T. Hirose, W. Hirose, M. Harigai, K. Suzuki, M. Kawakami, H. Tabata, M. Kawagoe, and H. Nakamura. 1987. Inhibitory effect of human recombinant interleukin-1 alpha and beta on growth of human vascular endothelial cells. Biochem. Biophys. Res. Commun. 145:969-75. 